\title{
Porcine head response to blast
}

\section{Jay K. Shridharani ${ }^{1}$ *, Garrett W. Wood ${ }^{1}$, Matthew B. Panzer ${ }^{1}$, Bruce P. Capehart ${ }^{2}$, Michelle K. Nyein ${ }^{3}$, Raul A. Radovitzky' and Cameron R. 'Dale' Bass'}

${ }^{1}$ Injury Biomechanics Laboratory, Department of Biomedical Engineering, Duke University, Durham, NC, USA

${ }^{2}$ Department of Psychiatry and Behavioral Sciences, Durham VA Medical Center, Duke University Medical Center, Durham, NC, USA

${ }^{3}$ Department of Aeronautics and Astronautics, Institute for Soldier Nanotechnologies, Massachusetts Institute of Technology, Cambridge, MA, USA

\section{Edited by:}

Ibolja Cernak, University of Alberta,

Canada

Reviewed by:

Reuben H. Kraft, U.S. Army Research Laboratory, USA

Andrew Merkle, Johns Hopkins

University Applied Physics

Laboratory, USA

*Correspondence:

Jay K. Shridharani, Department of

Biomedical Engineering, Duke

University, 136 Hudson Hall, Durham,

NC 27705, USA.

e-mail: jay.shridharani@duke.edu
Recent studies have shown an increase in the frequency of traumatic brain injuries related to blast exposure. However, the mechanisms that cause blast neurotrauma are unknown. Blast neurotrauma research using computational models has been one method to elucidate that response of the brain in blast, and to identify possible mechanical correlates of injury. However, model validation against experimental data is required to ensure that the model output is representative of in vivo biomechanical response. This study exposes porcine subjects to primary blast overpressures generated using a compressed-gas shock tube. Shock tube blasts were directed to the unprotected head of each animal while the lungs and thorax were protected using ballistic protective vests similar to those employed in theater. The test conditions ranged from 110 to $740 \mathrm{kPa}$ peak incident overpressure with scaled durations from 1.3 to $6.9 \mathrm{~ms}$ and correspond approximately with a $50 \%$ injury risk for brain bleeding and apnea in a ferret model scaled to porcine exposure. Instrumentation was placed on the porcine head to measure bulk acceleration, pressure at the surface of the head, and pressure inside the cranial cavity. Immediately after the blast, 5 of the 20 animals tested were apneic. Three subjects recovered without intervention within $30 \mathrm{~s}$ and the remaining two recovered within $8 \mathrm{~min}$ following respiratory assistance and administration of the respiratory stimulant doxapram. Gross examination of the brain revealed no indication of bleeding. Intracranial pressures ranged from 80 to $390 \mathrm{kPa}$ as a result of the blast and were notably lower than the shock tube reflected pressures of $300-2830 \mathrm{kPa}$, indicating pressure attenuation by the skull up to a factor of 8.4. Peak head accelerations were measured from 385 to $3845 \mathrm{G}$ 's and were well correlated with peak incident overpressure $\left(R^{2}=0.90\right)$. One SD corridors for the surface pressure, intracranial pressure (ICP), and head acceleration are presented to provide experimental data for computer model validation.

\section{INTRODUCTION}

Exposure to blasts from explosive devices in the ongoing conflicts in Iraq and Afghanistan has become the most common cause of injury to American soldiers (Okie, 2005; Warden et al., 2005). Shock waves produced from explosives are known to cause a variety of injuries (Hooker, 1924). Traditional blast injury research has focused on injuries to the air-filled organs, such as the pulmonary system, ear, and gastrointestinal tract, as these have been found to be most susceptible to primary blast overpressure (Bowen et al., 1968; Bass et al., 2008). However, recent studies have shown a decrease in the frequency of tympanic membrane and pulmonary injury due to primary blast despite the higher incidence of blast exposure (Ritenour and Baskin, 2008). Conversely, there has been an increase in traumatic brain injury attributed to blast exposure (Kennedy et al., 2007). This shift in injury location is likely due to the extensive use of personal protective equipment including ballistic protective vests (Cooper, 1996). Ballistic protective vests are known to attenuate blast overpressure seen by the thorax, therefore decreasing pulmonary injury risk below that of the head (Wood et al., 2012).
Many studies have investigated the phenomenology associated with blast-induced brain injury (e.g., Cernak et al., 2001, 2011; Chavko et al., 2007; Rafaels et al., 2011). However, comparison of these studies can be confounded by important methodological differences in the applied blast overpressure conditions, and the inability to reproduce realistic blast scenarios (Bass et al., 2012). For example, some animal models are limited because the thorax is left exposed to the blast wave, possibly leading to significant pulmonary barotrauma effects (c.f. Long et al., 2009) and possible subsequent brain pathology (Iacobone et al., 2009). Additionally, many small animal models (rodents) are exposed to long scaled overpressure durations and high overpressure impulses outside the realm of contemporary combat situations (Cernak et al., 2001; Pun et al., 2011). It is important that blast TBI research focuses on realistic exposure levels that accurately represent current threats in a combat environment or from terrorism.

A major goal in blast injury research is to develop injury criteria based on characteristic parameters of the impinging blast wave (c.f. Bass et al., 2012). Historically, injury risk assessment models for pulmonary injury and/or lethality have been developed based on peak overpressure and duration, as well as repeated exposure 


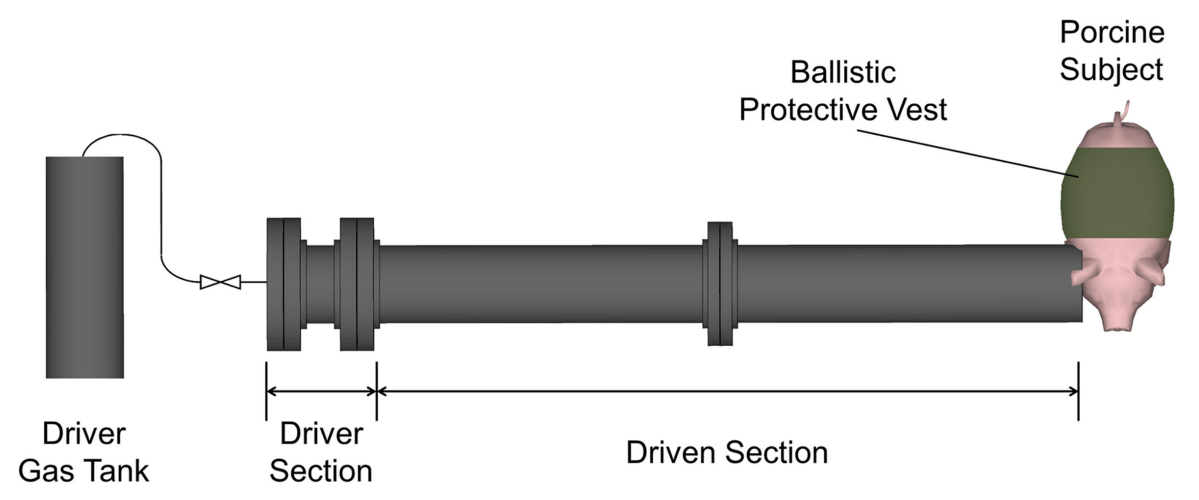

FIGURE 1 | Shock tube and test setup schematic.

(Bowen et al., 1968; Bass et al., 2008; Panzer et al., 2012c). These studies have utilized Bowen's duration scaling technique (Bowen et al., 1968) to correlate animal injury response to human injury response. Despite the reasonable assumption that a similar injury risk assessment based on external blast parameters would exist for the brain, current data on the mechanical correlates resulting in blast brain injury risk is limited. Ferret and rabbit brain injury risk functions (Rafaels, 2011; Rafaels et al., 2011) were developed providing risk functions for apnea, mild/moderate/severe brain bleeding, and fatality as a function of the blast overpressure and duration. However, clarifying injury risk requires additional data from larger ranges of blast dose and additional animal sizes.

Computational blast modeling may help elucidate the response of the head and brain in animal injury models, and later in human models. Previous numerical modeling efforts suggest that direct propagation of stress waves via soft-tissue pathways may exacerbate the pressure effects seen inside the brain (Moore et al., 2009; Nyein et al., 2010). Other studies suggest that skull flexure from blast impact is a potential source of injury (e.g., Moss et al., 2009), or that cerebrospinal fluid cavitation intensifies the deformation of the periventricular tissues (Panzer et al., 2012b). However, care must be taken when numerically modeling blast loading conditions. Blast model responses for biological materials are sensitive to mesh size and element formulation (Panzer et al., 2012a), so efforts must be taken to design models that show sufficient mesh convergence. An essential limitation of these models is lack of validation data.

Recognizing the current limitations in blast-induced brain injury research, there is a motivation to test larger animals with more operationally relevant overpressure durations, and validate computational models with results from these realistic conditions. The resulting data should provide insight into the human response to realistic blast threats and provide mechanical correlates to injury that cannot be obtained experimentally. The goal of this study is to evaluate the mechanical head response of a large animal with similar body mass to a human when subjected to primary blast waves. This study exposed the animal's head to pressure waves generated by a shock tube while protecting the pulmonary system with a soft ballistic protective vest similar to body armor worn by current military personnel in theater. We hypothesized that the skull acts to attenuate pressure, decreasing the local transient intracranial pressure (ICP) compared to pressures in the free field.

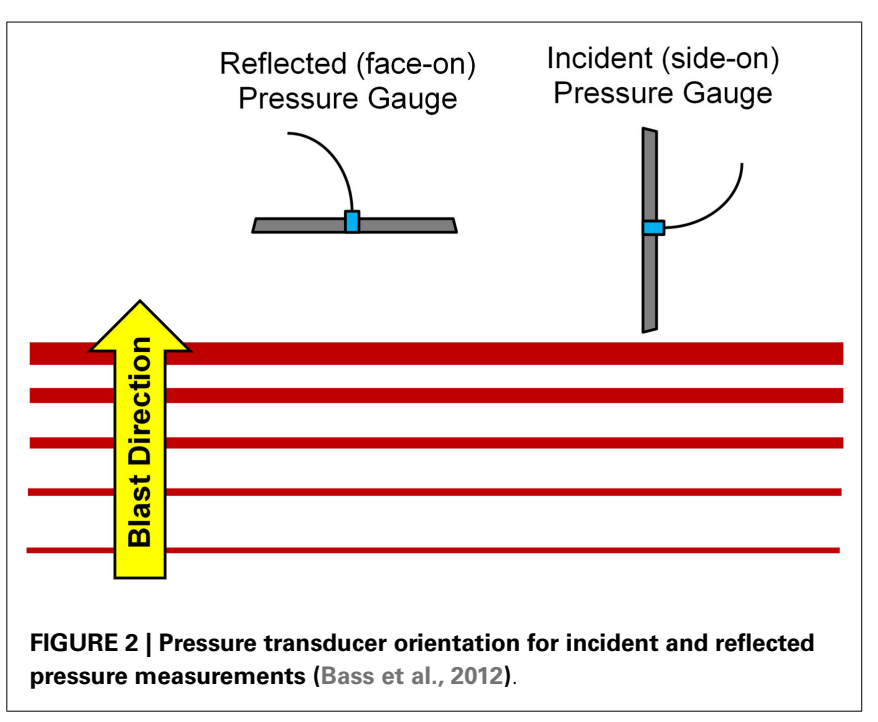

\section{MATERIALS AND METHODS}

A 305-mm diameter shock tube (Figure 1) was used to generate planar shock waves representative of real-world blasts from open-field, uncased high explosives. The overpressure and positive phase duration were controlled by varying the diaphragm thickness separating the driver and driven sections of the shock tube (from 0.00025 to $0.0056 \mathrm{~mm}$ ), and by varying the driver section length (from 305 to $610 \mathrm{~mm}$ ). Overpressure was measured using three flush-mounted pressure transducers (Endevco 8530B, San Juan Capistrano, CA, USA) in an incident (side-on) pressure configuration. Transducers were evenly spaced around the tube circumference $1 / 4^{\prime \prime}$ interior to the tube exit. Repeated tests showed an $8 \%$ SD in peak overpressure for a given membrane thickness. From CONWEP calculations (Hyde, 2004), the overpressure conditions were comparable to survivable blasts (c.f. Bass et al., 2008) produced by 105 and $155 \mathrm{~mm}$ artillery rounds at a range of $1-5 \mathrm{~m}$ and up to $50 \mathrm{~kg}$ of TNT-equivalent high explosive at a range of $7-10 \mathrm{~m}$. The incident pressure was measured in the tube and the reflected pressure was measured in the brain. This difference is due to the sensor orientation at these locations (Figure 2). For comparison to ICP, the peak incident pressure of the applied shock tube blast was converted to reflected pressure using the ideal gas Rankine-Hugoniot relations 
(Iremonger, 1997). This relationship is a function of reflected pressure $\left(P_{\mathrm{R}}\right)$, incident pressure $\left(P_{\mathrm{I}}\right)$ and atmospheric pressure $\left(P_{\mathrm{A}}\right)$ as:

$P_{\mathrm{R}}=2 P_{\mathrm{I}}\left(\frac{7 P_{\mathrm{A}}+4 P_{\mathrm{I}}}{7 P_{\mathrm{A}}+P_{\mathrm{I}}}\right)$

Twenty live, anesthetized Yorkshire pigs (Sus scrofa) were exposed to the shock tube generated blast waves at various conditions (Table 1) to determine the dynamic response of the head and brain. Additionally three animals were tested as controls without a blast. The total body mass of the animal subjects was $61.0 \pm 6.0 \mathrm{~kg}$. All procedures involving animals were approved by the Duke University Institutional Animal Care and Use Committee. For pain management each animal was provided with a transdermal fentanyl patch $(2 \mu \mathrm{g} / \mathrm{kg}) 24 \mathrm{~h}$ prior to testing. Induction anesthetics used were telazol $(4.4 \mathrm{mg} / \mathrm{kg}$ IM) and xylazine $(2.2 \mathrm{mg} / \mathrm{kg}$ IM), with propofol $(4-8 \mathrm{mg} / \mathrm{kg} / \mathrm{h})$ for maintenance. Bupivacaine $(0.25 \%$ concentration) was used for local anesthesia prior to surgical procedures. Normosol $(2 \mathrm{cc} / \mathrm{kg} / \mathrm{h})$ was provided for fluid support during testing procedures.

The pigs were restrained prone on a stainless steel lift table. The animal's head was lifted above the table surface and placed onto an aerodynamic aluminum plate to reduce the effect of reflected pressure waves, which is more representative of free field blasts. The head was secured to the aluminum plate and placed $5.3 \pm 1.5 \mathrm{~cm}$ from the shock tube to prevent any secondary impacts with the tube. The axial centerline of the shock tube in the open face was aligned with the right ear surface pressure gauge on the animal subject and normal to the right temporal bone (Figure 1). Cranial thickness was considered a contributing factor to the blast wave transmission from air to brain. Accordingly, the parietal skull, which has similar thickness to that of humans, was positioned perpendicular to the blast wave front. In humans, average parietal skull thickness is $6.57 \pm 1.31 \mathrm{~mm}$ for males and $7.23 \pm 1.68 \mathrm{~mm}$ for females (Ross et al., 1998) compared to $9.74 \pm 1.74 \mathrm{~mm}$ (Rafaels, unpublished data) in $80 \mathrm{~kg}$ female pigs. The detailed age variation of porcine skull thickness with developmental size is unknown. However, human length scaling (Loyd et al., 2010) may be used with human developmental scaling (Rollins et al., 2010) to estimate the effect of skull thickness changes between 60 and $80 \mathrm{~kg}$ pigs. Assuming $80 \mathrm{~kg}$ pigs are developmentally adult comparable to 20-year-old humans, the change in skull thickness between 60 and $80 \mathrm{~kg}$ is less than $5 \%$ in humans over similar developmental ranges.

The thorax was positioned away from the direct exposure from the shock tube (Figure 1) and further protected using a policeissue ballistic vest at NIJ Level-2 (PACA-2, Protective Apparel Corporation of America, Jacksboro, TN, USA). The hard ceramic plate inserts do not fit the torso shape of the pigs and therefore were not used in this study. The position of the torso along with the pressure attenuation of the soft armor should have effectively isolated the shock wave to the head and brain. To compare the responses of subsequent animals, mass scaling rules based on pulmonary blast injury models (Bowen et al., 1968) were used to scale the positive phase duration to a 70-kg human reference level. This scaling law is based on the cubed root of body mass, and is similar

Table 1 | Test matrix of shock conditions and number of repeated tests.

\begin{tabular}{|c|c|c|c|c|}
\hline Condition number & Incident overpressure (kPa) & Duration (ms) & Impulse (kPa-ms) & Number of tests \\
\hline 1 & 107 & 1.3 & 47 & 1 \\
\hline 2 & 181 & 2.1 & 83 & 2 \\
\hline 4 & 233 & 5.6 & 302 & 1 \\
\hline 5 & 251 & 3.7 & 302 & 3 \\
\hline 8 & 741 & 3.4 & 869 & 1 \\
\hline 9 & & (no blast dose) & & 3 \\
\hline
\end{tabular}

Table 2 | Transducers and their anatomical locations.

\begin{tabular}{|c|c|c|}
\hline Sensor & Model number & Location \\
\hline Right side surface pressure & Kulite LQ-125 & $1.05 \pm 0.32 \mathrm{~cm}$ anterior to the opening of the ear \\
\hline Nuchal crest surface pressure & Kulite LQ-125 & $0.88 \pm 0.38 \mathrm{~cm}$ posterior to nuchal crest in the midsagittal plane \\
\hline Left side surface pressure & Kulite LQ-125 & $1.08 \pm 0.33 \mathrm{~cm}$ anterior to the opening of the ear \\
\hline Right parietal pressure & Millar SPR-524 & $2.41 \pm 0.26 \mathrm{~cm}$ anterior to the nuchal crest and $2.33 \pm 0.57 \mathrm{~cm}$ lateral to the midsagittal plane \\
\hline Frontal lobe pressure & Millar SPR-524 & $2.40 \pm 0.31 \mathrm{~cm}$ anterior to the nuchal crest in the midsagittal plane \\
\hline Left parietal pressure & Millar SPR-524 & $2.39 \pm 0.33 \mathrm{~cm}$ anterior to the nuchal crest and $2.56 \pm 0.51 \mathrm{~cm}$ lateral to the midsagittal plane \\
\hline Accelerometer array & $\begin{array}{l}\text { Endevco } 7270 \mathrm{~A} \text { and } \\
\text { DTS ARS-50k }\end{array}$ & $4.32 \pm 0.94 \mathrm{~cm}$ anterior to the nuchal crest in the midsagittal plane \\
\hline
\end{tabular}


to length scaling rules used for blunt impacts (Eppinger et al., 1984):

$T_{\text {scaled }}=T_{\text {measured }}\left(\frac{70}{M_{\text {measured }}}\right)^{\frac{1}{3}}$

Following the blast, the pigs were monitored for up to $5 \mathrm{~h}$ prior to euthanasia. If post-blast apnea was observed and did not resolve spontaneously or with pharmaceutical aid, the pig was placed on an oxygen ventilator. Full necropsies were performed to look for gross pathology to the organ systems and detailed brain histopathology was performed. These results will be reported elsewhere.

To ensure the rigid mounting of the accelerometer package, a $5-\mathrm{cm} \times 5-\mathrm{cm}$ section of scalp was removed anterior to the nuchal crest. A $2.16-\mathrm{cm} \times 2.16-\mathrm{cm} \times 1.09-\mathrm{cm}$ aluminum block instrumented with three piezoresistive linear accelerometers (Endevco 7270A) and one angular rate sensor (ARS-50K, DTS, Seal Beach, CA, USA) was rigidly mounted to the exposed skull with its center $4.32 \pm 0.94 \mathrm{~cm}$ anterior to the nuchal crest. The angular rate sensor was oriented to measure coronal plane rotation. The $X$-axis is defined in the plane of the surface of the pig skull parallel to the shock tube face, the $Y$-axis is defined in the axial direction of the shock tube, and the $Z$-axis is normal to the surface of the pig skull at the location of the sensor mounting block.

External pressure response was measured using three surface pressure gauges (LQ-125, Kulite Semiconductor Products Inc., Leonia, NJ, USA) sutured to the skin surface: one at the intersection of the nuchal crest and the midsagittal plane (nuchal crest surface pressure) and the other two $1 \mathrm{~cm}$ anterior to the opening of each ear (left and right side surface pressure). ICP response

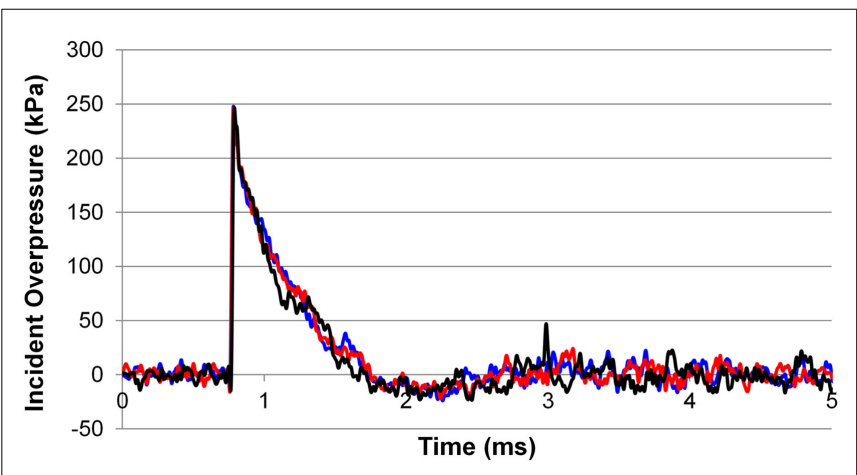

FIGURE 3 | Example trace of the incident overpressure time history measured at locations $120^{\circ}$ apart $1 / 4^{\prime \prime}$ from the end of the shock tube.

Table 3 | Shock wave test conditions, injury data, and HIC for each animal test.

\begin{tabular}{|c|c|c|c|c|c|c|c|c|}
\hline Test number & Mass (kg) & $\begin{array}{l}\text { Peak incident } \\
\text { overpressure (kPa) }\end{array}$ & $\begin{array}{l}\text { Scaled } \\
\text { duration (ms) }\end{array}$ & $\begin{array}{l}\text { Impulse } \\
\text { (kPa-ms) }\end{array}$ & $\begin{array}{l}\text { Peak head } \\
\text { acceleration (G) }\end{array}$ & HIC & $\begin{array}{l}\text { HIC } \\
\text { duration (ms) }\end{array}$ & $\begin{array}{l}\text { Apnea } \\
\text { (yes/no) }\end{array}$ \\
\hline 1 & 59 & 473 & 3.04 & 528 & 2279 & 5783 & 0.78 & No \\
\hline 2 & 70 & 242 & 3.51 & 301 & 1314 & 1554 & 4.53 & Yes $^{2}$ \\
\hline 3 & 70 & 741 & 3.44 & 869 & 3845 & 27192 & 1.23 & Yes $^{2}$ \\
\hline 4 & 48 & Control & Control & Control & - & - & - & No \\
\hline 5 & 61 & 186 & 2.13 & 87 & - & - & - & No \\
\hline 6 & 65 & Control & Control & Control & - & - & - & No \\
\hline 7 & 59 & 227 & 2.68 & 186 & - & - & - & No \\
\hline 8 & 59 & 177 & 2.68 & 186 & 637 & 489 & 7.75 & No \\
\hline 9 & 57 & 260 & 3.78 & 324 & 1412 & 3592 & 5.53 & Yes $^{1}$ \\
\hline 10 & 59 & 177 & 2.16 & 88 & 902 & 419 & 2.57 & No \\
\hline 11 & 59 & 250 & 3.73 & 320 & 1013 & 1761 & 5.63 & Yes $^{1}$ \\
\hline 12 & 59 & 107 & 1.28 & 50 & 358 & 169 & 6.33 & No \\
\hline 13 & 59 & 233 & 5.57 & 319 & 897 & - & - & No \\
\hline 14 & 57 & 278 & 6.88 & 582 & - & - & - & No \\
\hline 15 & 59 & 269 & 6.79 & 574 & - & - & - & No \\
\hline 16 & 61 & 272 & 6.70 & 567 & - & - & - & No \\
\hline 17 & 61 & Control & Control & Control & - & - & - & No \\
\hline 18 & 56 & 239 & 2.74 & 190 & 1303 & 541 & 1.73 & No \\
\hline 19 & 55 & 501 & 3.13 & 542 & 3389 & 4909 & 1.19 & No \\
\hline 20 & 56 & 525 & 3.10 & 538 & 3831 & 9790 & 4.67 & No \\
\hline 21 & 57 & 274 & 6.87 & 581 & 1001 & 3505 & 15.00 & Yes $^{1}$ \\
\hline 22 & 51 & 501 & 3.20 & 555 & 2601 & 4785 & 4.41 & No \\
\hline 23 & 90 & 234 & 2.33 & 162 & 880 & 918 & 6.63 & No \\
\hline
\end{tabular}

${ }^{1}$ Recovered from apnea within $60 \mathrm{~s}$.

${ }^{2}$ Recovered from apnea within $8 \mathrm{~min}$. 
was measured using catheter pressure transducers (SPR-524, Millar Instruments, Inc., Houston, TX, USA) inserted through three $4 \mathrm{~mm}$ holes in the exposed portion of skull. Table 2 provides a summary of the instrumentation and sensor location used in this study. All data was recorded using a data acquisition system (meDAQ, Hi-Techniques, Madison, WI, USA) sampling at $1 \mathrm{MHz}$ with a $500-\mathrm{kHz}$ hardware anti-aliasing filter and post-processed with an 8-pole unbiased Butterworth filter with a $40-\mathrm{kHz}$ cutoff frequency.

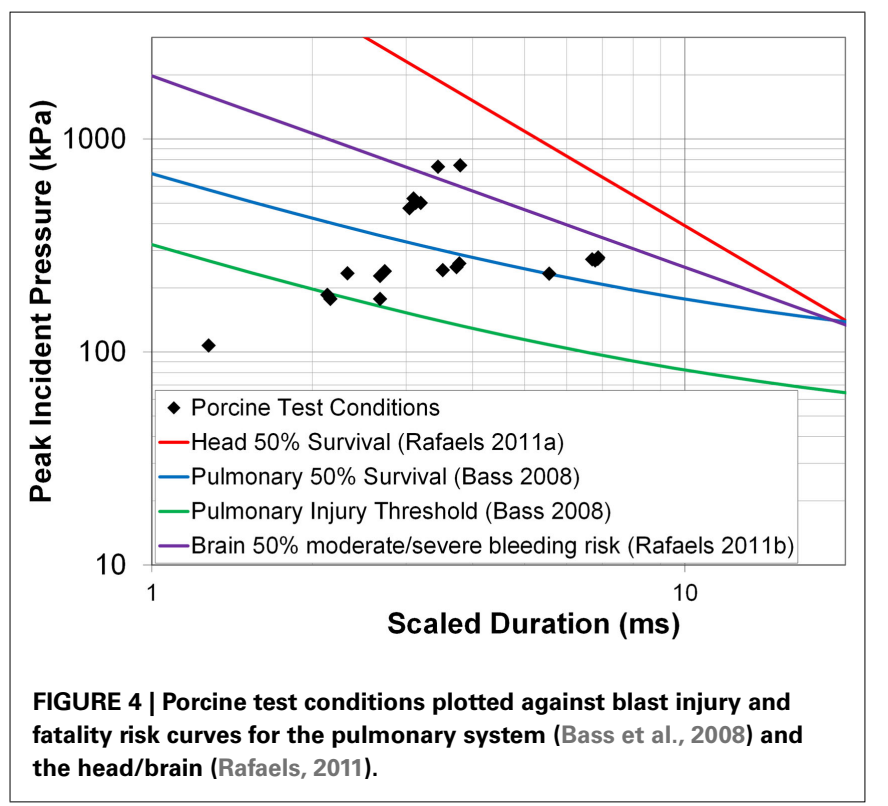

Acceleration-time histories were low-pass filtered at $1650 \mathrm{~Hz}$ (Society of Automotive Engineers, 1995) according to automotive standards (United States Department of Transportation, 2006) and analyzed using the head injury criterion (HIC), which is based on animal concussions and cadaveric skull fractures (Versace, 1971):

$\mathrm{HIC}=\left(\frac{\int_{t_{1}}^{t_{2}} a(t) d t}{t_{2}-t_{1}}\right)^{2.5}\left(t_{2}-t_{1}\right)$

Head injury criterion was calculated using the head surface acceleration, which is approximately equal to the head center of gravity (CG) acceleration under the assumption of low rotational velocities and minimal skull deformation. HIC does not account for rotational velocities, nor has it been validated to blast loading.

\section{RESULTS}

The incident overpressure (Figure 3) measured at the exit of the shock tube was characterized by a sharp rise in pressure followed by an exponential decay. These time histories were used to determine the peak incident overpressure, positive phase duration, and pressure impulse for each test (Table 3). Scaled to the lower mass of ferrets, these blast exposures (Figure 4) were strong enough to cause pulmonary injury (c.f. Bass et al., 2008) and brain hemorrhage in ferrets (c.f. Rafaels, 2011). The incident shock tube pressure was converted to reflected pressure (Figure 5) to compare to the reflected pressure measurements at the head surface and in the cranial cavity. Results showed that pressure is attenuated as the wave travels through the skull and into the brain. This attenuation of pressure held true for each test (Figure 6). For each test condition the reflected pressure in the shock tube was statistically significantly larger than at each ICP location (matched

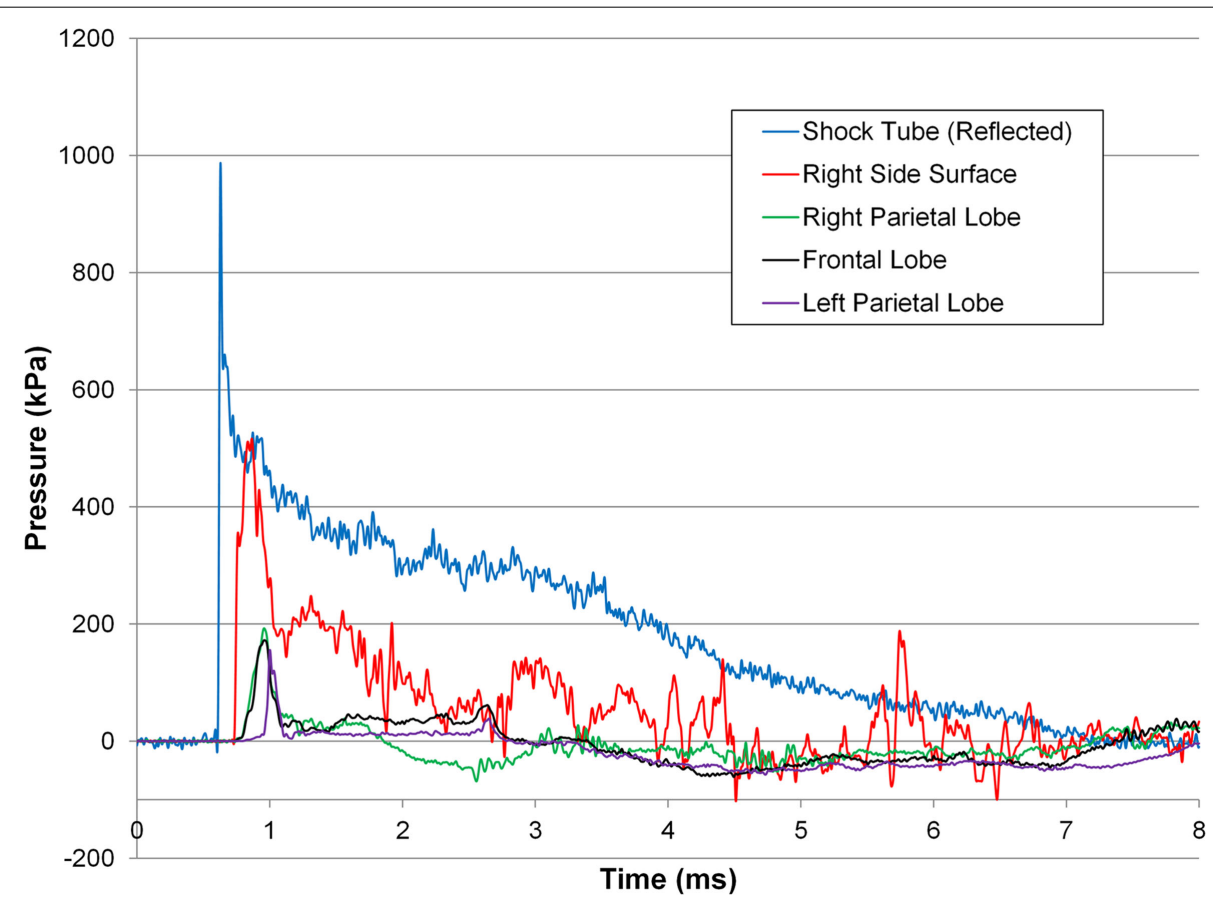

FIGURE 5 | Pressure response for a $274 \pm 6.9-\mathrm{kPa}$ peak incident overpressure $6.72 \pm 0.55$-ms positive phase duration shock wave. 


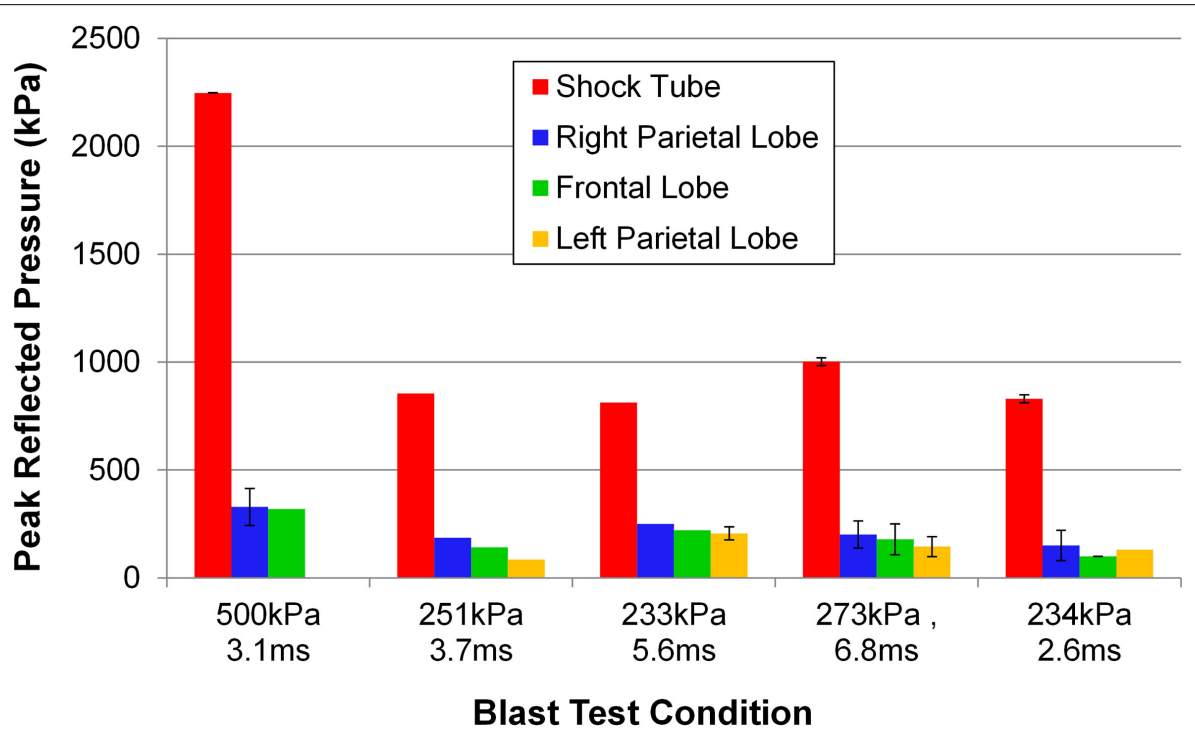

FIGURE 6 | Pressure measured at the surface of the porcine head and the intracranial pressure measured at various locations for a shock impacting the right side of the pig's head. The blast test conditions vary in peak incident overpressure and positive phase duration.
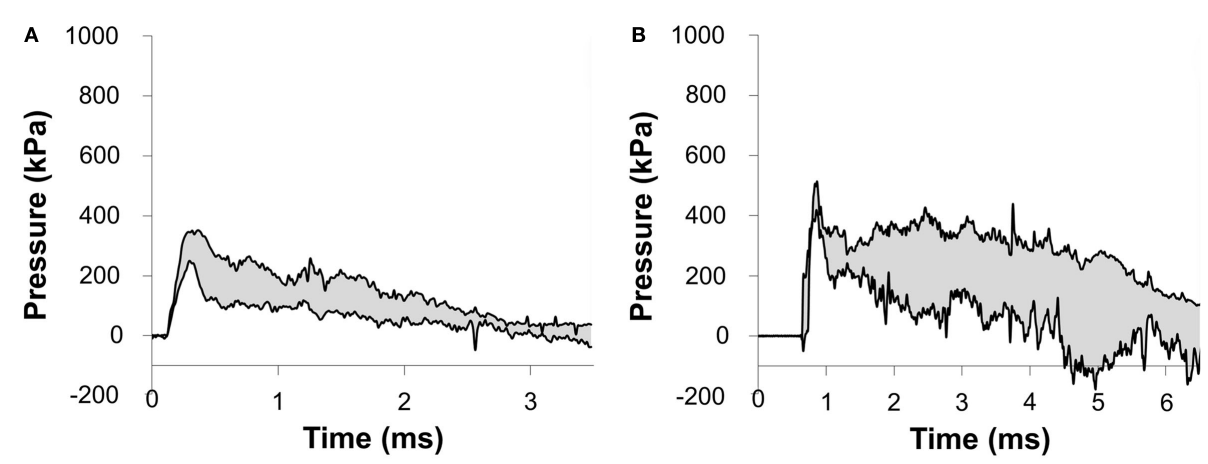

FIGURE 7 | Corridors for the pressure at the surface of the porcine head impacted with (A) a 217-kPa peak overpressure with a 2.5-ms positive phase duration and (B) a 273-kPa peak overpressure with a 6.4-ms positive phase duration incident shock wave.

pair $t$-test, $p=0.0001)$. The $500-\mathrm{kPa}, 3.1 \mathrm{~ms}$ tests were not instrumented with left parietal pressure gauges and therefore were not included in the results. The time histories of repeated tests were temporally aligned at the onset of overpressure and 1 SD corridors for the surface pressure (Figure 7) and ICP (Figure 8) were generated.

An example time history of the head acceleration response along with the surface pressure and incident pressure converted to reflected pressure are shown (Figure 9). The $y$-acceleration was the dominant component contributing to the resultant and was characterized by a sharp rise, offset in time from the incident overpressure and surface pressure, followed by the vibrational mode(s) of the head. The rotational rate sensor failed to capture the response of the animal subject's head due to saturation of the signal and therefore these measurements were not included in the analysis.

Peak resultant acceleration and peak incident overpressure correlated well $\left(R^{2}=0.90\right.$, Figure 11). Positive phase duration was not a significant predictor of the peak acceleration $(p=0.30)$ and was removed from the final model. The linear model was strongly correlated $\left(R^{2}=0.88, p<0.0001\right)$ in the form: $a=b P$ where $\mathrm{a}$ is the peak head acceleration in $G, P$ is the peak incident overpressure in $\mathrm{kPa}$, and $b$ is the linear model coefficient of $5.446 \pm 0.285 \mathrm{G} / \mathrm{kPa}$. Acceleration corridors (Figure 10) were generated based on the mean and SD of the acceleration-time history in the $y$-direction.

Head injury criterion correlated well with peak incident overpressure using a log-linear model in the form $\log (\mathrm{HIC})=a P+b$ (Figure 12, Eq. $4, R^{2}=0.83, p<0.0001$ ) and each model parameter was statistically significant $(p<0.05)$. The HIC calculated (Table 3) exceeded the automobile standard of 1000 set by the National Highway Traffic Safety Administration (NHTSA), corresponding to a $47 \%$ risk of skull fracture (Kleinberger et al., 1998).

$\log (\mathrm{HIC})=\left[(3.09 \pm 0.40) 10^{-3}\right]^{\star} p+(2.27 \pm 0.15)$ 
Apnea was exhibited immediately post-blast in five animals. Three animals returned to a normal physiological state within $30 \mathrm{~s}$ while the remaining animals returned to normal within $8 \mathrm{~min}$ following onset. Macroscopic examination of the lungs and brain showed no damage or edema in any of the animals, indicating that the personal protective equipment protected the lungs from overt blast injury. Despite the scaled test conditions falling above the $50 \%$ risk of mild meningeal bleeding for ferrets, and close to the $50 \%$ risk of severe meningeal bleeding for ferrets (Rafaels, 2011), no brain bleeding was seen in the porcine tests.

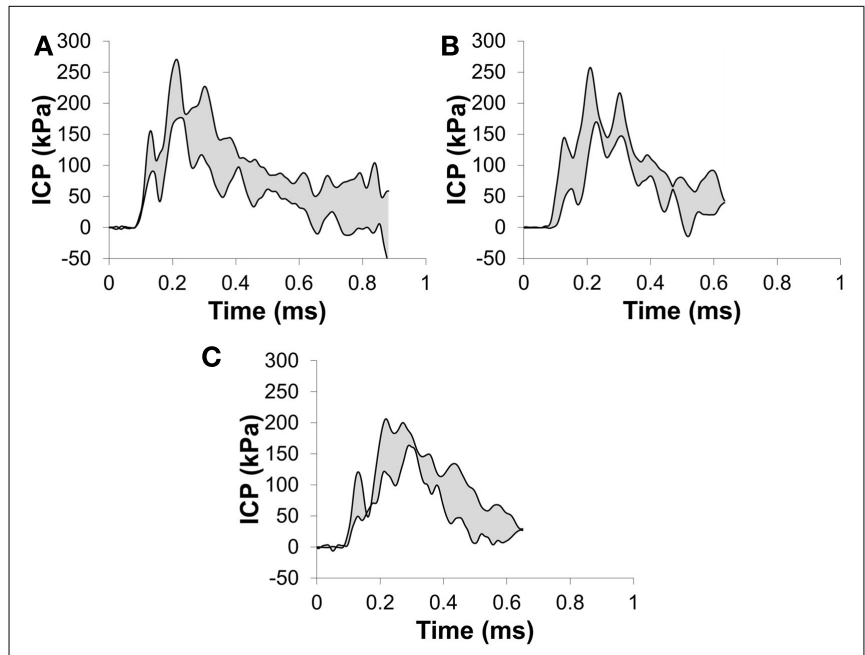

FIGURE 8 | Corridors for the pressure in (A) the right parietal lobe, (B) the frontal lobe, and (C) the left parietal lobe for a 273-kPa peak overpressure with a 6.4-ms positive phase duration incident shock wave.

\section{DISCUSSION}

This study exposed live porcine subjects to blast loading at various pressure and duration levels. The blast waves were generated using a shock tube with output controlled by changing the driver section length and rupture diaphragm thickness. The shock wave impacted the right temporal region of live porcine subjects' heads while the thorax was shielded using a ballistic protective vest. All blast test conditions were compared to ConWep (Hyde, 2004) calculations (Figure 13) for a hemispherical surface detonation showing blast overpressures and durations similar to those typical of a small improvised explosive device (IED), a medium IED, and a car bomb, with each line in Figure 13 indicating the corresponding overpressure levels at varying standoff distances.

The blast wave overpressure and duration conditions in this test series were selected to correspond with the scaled 50\% risk of severe bleeding and $50 \%$ risk of apnea from ferret to porcine body mass (Rafaels, 2011). However, no brain bleeding was found upon macroscopic inspection of the intact brain and sliced brain surfaces. These results may indicate that the Bowen technique for scaling blast exposure between animals (Bowen et al., 1968) may not be appropriate for brain bleeding between pigs and ferrets. The observed difference between predicted and experimental results is possibly due to anthropometric differences between pigs and ferrets. Compared to ferrets, pigs have a thicker diploic skull with multiple changes in the mechanical characteristics that likely provide increased pressure attenuation.

Previous studies have exposed pigs to primary blast from explosive charges and observed apnea onset following blast without corresponding brain bleeding (Suneson et al., 2000; Bauman et al., 2009; Cernak et al., 2011). However, it is difficult to directly compare results due to methodological differences,

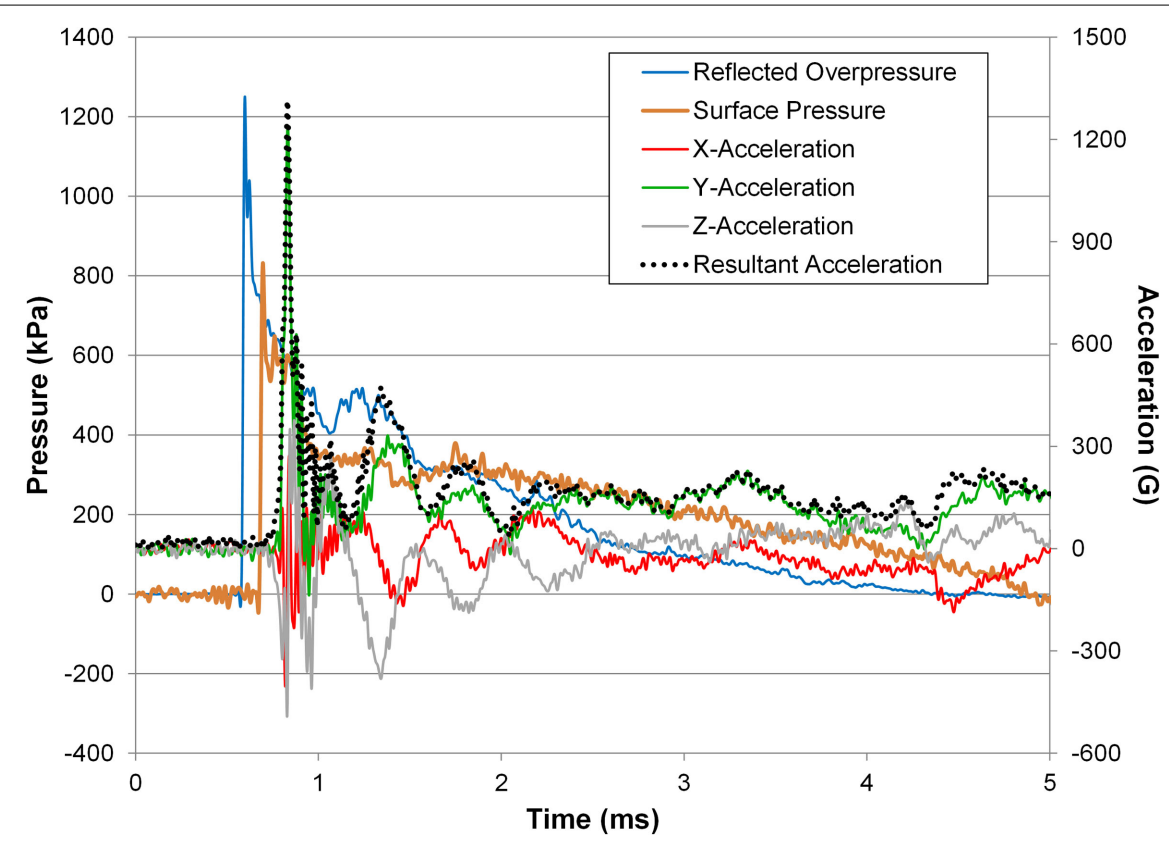

FIGURE 9 | Head acceleration response for a 242-kPa average peak overpressure and 3.52 ms positive phase duration shock wave. 
including large pressure reflections from proximal walls not characteristic of free field scenarios like the current study mimics.

The time histories of the reflected pressure in the free stream and pressure at the head surface were characteristic of shock loading indicated by the fast rise in pressure followed by an exponential decay. The pressure measured at the head surface was lower than the idealized reflected pressure of the incident wave because the surface of the head prevented the gauge from being mounted directly normal to the shock flow and because the gauge was mounted on a compliant surface. The lack of a secondary peak in the surface pressure gauge indicates the pig head was exposed to only one shock wave confirming our goal of representing free field conditions. Transmission of the shock

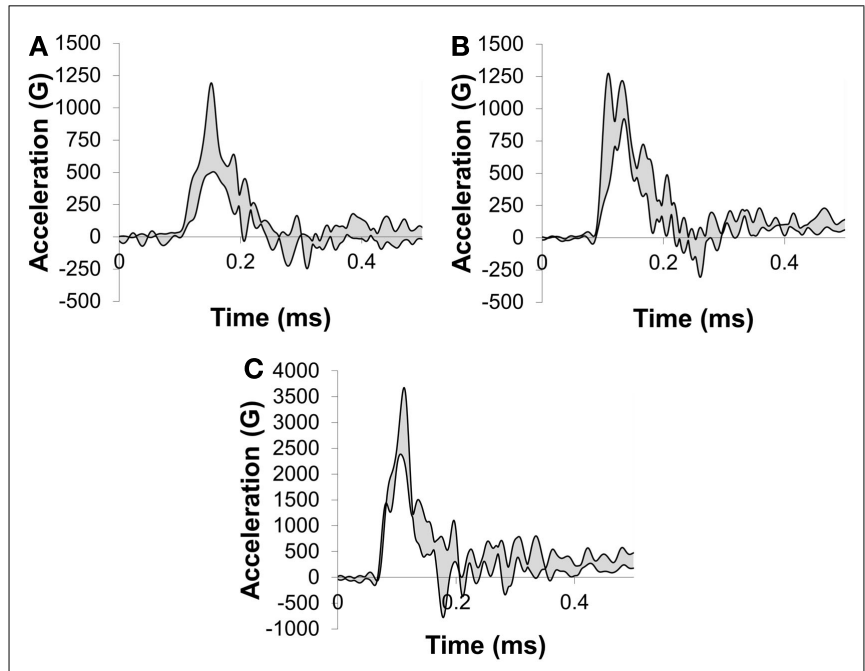

FIGURE $10 \mid y$-Acceleration corridors for a porcine head impacted with (A) a 217-kPa peak overpressure with a 2.5-ms positive phase duration, (B) $259 \mathrm{kPa}$ peak overpressure with a 3.5 -ms positive phase duration, and (C) a 509-kPa peak overpressure with a 2.9-ms positive phase duration incident shock wave. wave into the cranial cavity resulted in a pressure wave with a statistically significantly smaller peak than the idealized reflected pressure (Figures 5 and $\mathbf{6}, p=0.0001$ ) and characterized by a longer rise time when compared to the surface pressure response. This slower rise in pressure was likely due the shock converting to an acoustic pressure wave in the brain similar to prior studies of an air shock traveling through skull into brain (Clemedson and Pettersson, 1955) and from air into water (Henderson et al., 1990).

The acceleration of the head was characterized by a sharp rise temporally offset from the surface pressure likely due to the viscoelasticity of the animal's skin. Double integrating the head acceleration of the largest blast exposure showed a maximum head displacement of $7.5 \mathrm{~mm}$. Although the neck forces were not measured, the minimal head movement and loose coupling between the head and neck support the assumption of negligible influence of neck tension on the injury results.

The statistically significant pressure decrease across the skull was described by an attenuation ratio (Table 4), defined as the maximum pressure in the brain divided by the theoretical reflected pressure of the shock wave. Attenuation ratios were calculated on those tests instrumented with ICP transducers, and ranged between 0.12 and 0.31 (mean 0.20) and were lower than the 0.42 estimated from the work by Säljö et al. (2008) also using porcine subjects. The disparity was likely because of the differences in test conditions, which differed by almost two orders of magnitude in pressure. The pressure attenuation was expected due to the large difference in acoustic impedance between air (408 rayl) and bone ( 8 Mrayl; Raum et al., 2004) resulting in a majority of the shock wave being reflected from the air-head interface.

These results were contrary to several recent studies that have reported ICPs exceeding the pressure of the blast wave, which suggests that the skull and skull dynamics amplify the pressure response in the brain. Leonardi et al. (2011) reported peak ICPs in rodents that were 1.0-2.3 times larger than the peak pressure of the incident blast wave and suggested that global skull flexure was the source of the pressure increase. Similarly, Chavko et al. (2007)

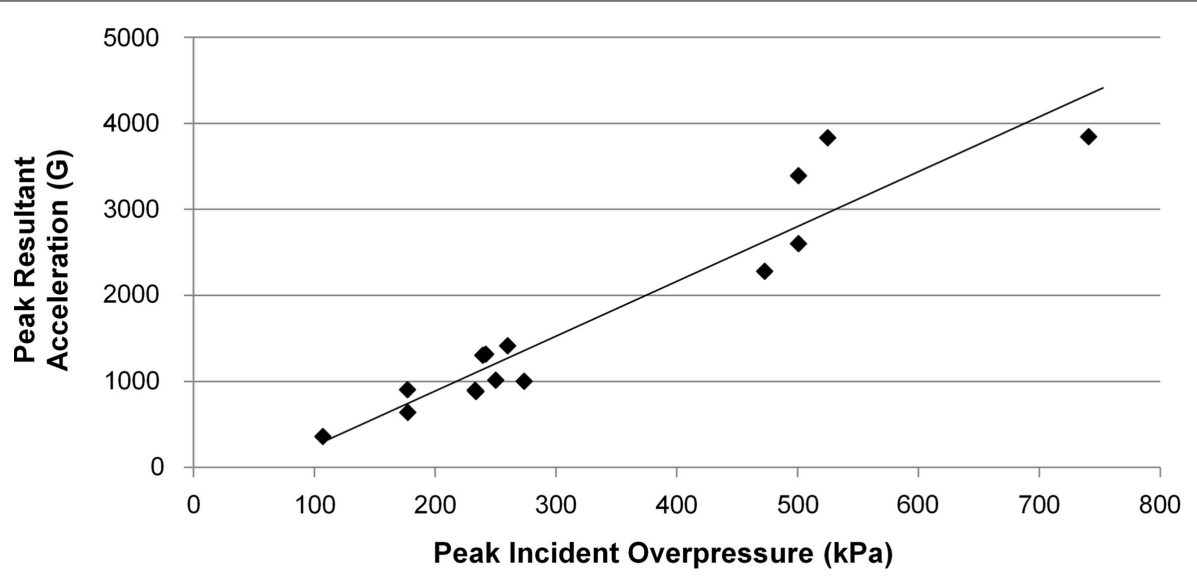

FIGURE 11 | Linear model for peak head resultant acceleration vs. peak incident overpressure $\left(R^{2}=0.904\right.$ and $\left.p<0.0001\right)$. 


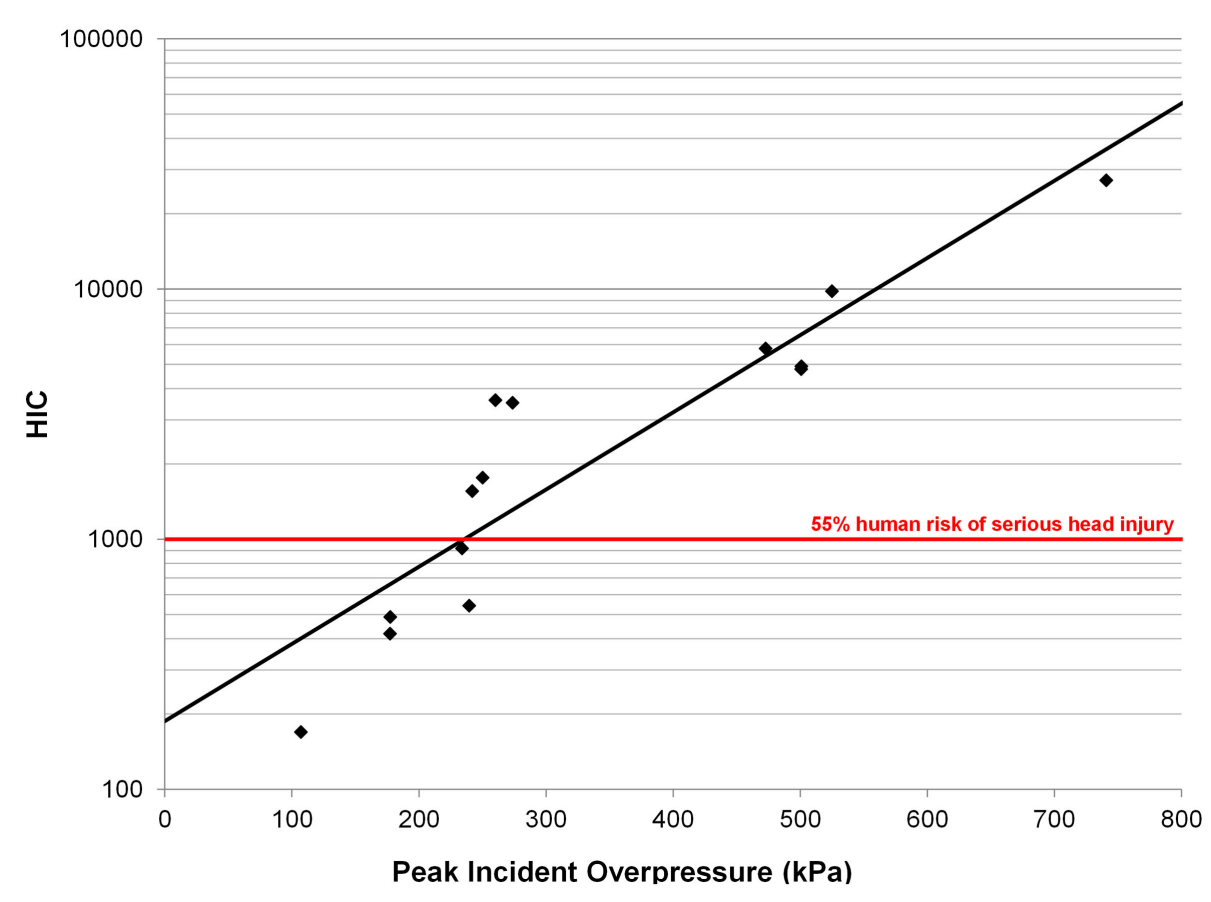

FIGURE 12 | Log-linear model for HIC vs. peak incident overpressure with an $R^{2}=0.97$ and $p<0.0001$.

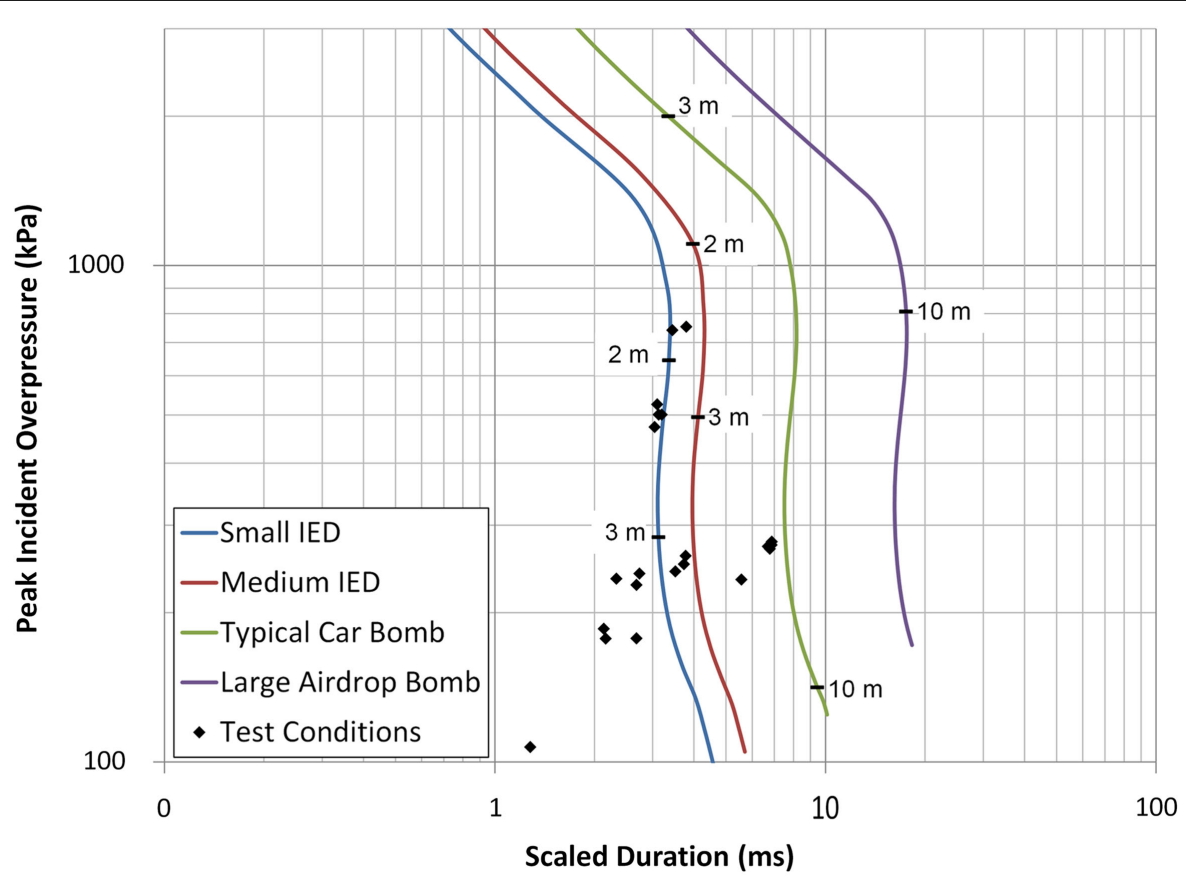

FIGURE 13 |The porcine test conditions plotted against the overpressure and duration conditions of realistic threats calculated using ConWep (Hyde, 2004).

reported comparable peak pressures between the free stream and in the brain. However, the conclusion that ICP is larger than the blast pressure is misleading because each of these studies compared the ICP with the incident "side-on" pressure of the blast wave. As previously mentioned, any incident blast wave that impinges on an object can theoretically increase between two and eight times during its reflection (Iremonger, 1997). Therefore, ICPs must be compared to the actual reflected surface pressure on the skull (the 
Table 4 | The shock exposure compared to the maximum pressure measured in the brain for tests in this study compared to those in prior literature (Säljö et al., 2008).

\begin{tabular}{lllll}
\hline Test & Test number & Peak reflected overpressure (kPa) & Peak brain pressure (kPa) & Attenuation ratio \\
\hline Säljö et al. (2008) & - & 22.4 & 9.3 & 0.42 \\
This study & 14 & 812.9 & 250.0 & 0.31 \\
This study & 24 & 816.5 & 99.7 & 0.12 \\
This study & 19 & 842.3 & 199.3 & 0.24 \\
This study & 2 & 854.1 & 185.2 & 0.22 \\
This study & 16 & 981.9 & 278.1 & 0.28 \\
This study & 17 & 996.3 & 205.5 & 0.21 \\
This study & 22 & 1005.3 & 125.8 & 0.13 \\
This study & 15 & 1025.0 & 192.6 & 0.19 \\
This study & 23 & 2246.8 & 389.1 & 0.17 \\
This study & 20 & 2247.5 & 267.6 & 0.12
\end{tabular}

theoretical reflected pressure if surface pressure is not available) or the comparison would be in error. Correctly comparing the ICPs with the estimated reflected pressures in previous studies would show that the pressures within the skull were lower than the pressures acting on the skull.

Numerical models may be helpful in evaluating head response to blast exposure, but experimental validation is required. This study provides surface pressure, ICP, and acceleration corridors. Specifically, the surface pressure can be used to validate the governing thermodynamics of shock propagation, while the ICP and acceleration corridors can be used to help validate the head and brain material properties, geometry, and mass distribution.

Brain injury criteria exist for rotational accelerations (e.g., Ommaya and Hirsch, 1971), however due to instrumentation difficulties rotational velocity measurements in this study did not yield meaningful results. The current technology for low-mass angular rate sensors suitable for blast-rate loading is limited, and the sensor used in this study saturated its signal with a magnitude of $100,000 \mathrm{deg} / \mathrm{s}$ oscillating at $8 \mathrm{kHz}$ for the duration of the response. Therefore, no assessment of current rotational acceleration injury criteria was performed. However, computational studies have suggested that etiology of brain tissue damage lies in the local strain gradients at tissue interfaces induced by the pressure and shear stress waves on the brain, indicating that any rotational criteria may be inappropriate for blast brain injury prediction.

Head injury criterion is a metric relating head acceleration to a risk of injury. The HIC value is widely used by the automotive industry in estimating head and brain injury risk for low-rate impacts. HIC measured at the head surface can be translated to the CG by correcting for the rotational velocity. Analysis of high-speed video showed minimal head rotation or deformation, indicating the acceleration measured at the head surface was representative of the translational response of the entire head. The automotive standard specifies a low-pass filter with a $1650-\mathrm{Hz}$ cutoff frequency based on low-rate impact tests. Unfortunately, this filter removes a majority of the frequency content in blast exposures known to have acceleration responses up to $40 \mathrm{kHz}$. HIC should be measured at the head CG, which is difficult in vivo. In addition, the
HIC duration approaches $1 \mathrm{~ms}$ for 4 of the 14 tests, with the limit of validity of the HIC model at approximately $1 \mathrm{~ms}$. A HIC value of 1000 correlates to a $47 \%$ risk of a skull fracture (Prasad and Mertz, 1985) for low-rate impacts. Our results show the HIC values calculated (Table 3) exceeded 1000 for 9 of the 14 pigs instrumented with accelerometers. However, none of the animals demonstrated any skull fracture, gross brain bleeding, or similar gross pathological evidence of brain injury. These results suggest the low-rate HIC is not appropriate for blast injury prediction.

This study was subject to limitations. A pig is dissimilar to a human in its morphology, mass distribution, and possibly material properties. Therefore, correlating the porcine pressure, acceleration, and injury response to human response can be difficult without scaling rules validated for blast loading. The porcine skull is generally curved relative to the incident shock, so the surface pressure gauges were oblique to the shock. The theoretical reflected pressure was used to calculate the ratio of peak ICP to peak shock pressure, which may alter the calculated ratio compared to a surface pressure measured normal to the incident shock. This should be considered in any future comparison studies or studies using these ratios as validation data. In addition, a shock tube has been utilized to produce a pressure wave similar in shape to an explosively generated pressure wave. However, a shock tube does not simulate the additional threats from high-velocity fragments, thermal exposure, and chemical by-products. Validation of numerical models can be performed by using the corridors presented. In a live animal model, accelerometers cannot be placed at the head CG without surgical intervention, and such interventions could have affected the physiological response to blast injury. We therefore reached conclusions about the head dynamics by measuring the dynamic response on the surface of the head. Translation of this surface acceleration to the CG acceleration can be made using angular acceleration measurements. Unfortunately, a sensor does not exist to conduct these measurements in blast scenarios.

The experimental results presented in this paper provide valuable data for the validation of computational models. In particular, these results show that, in the absence of a soft-tissue pathway for pressure propagation into the brain, ICPs are lower than the 
reflected overpressure at the head surface. Experimental data is provided which can be used to develop metrics for porcine blast TBI and pressure and acceleration validation data for numerical models. Based on the limited number of animal studies used for blast brain injury study, it appears that the simple Bowen scaling may not be well-suited for relating blast brain injury between pigs and smaller animals. It is likely that a blast brain scaling law will need to consider morphologic differences between species as additional factors beyond body or head mass.

\section{REFERENCES}

Bass, C., Panzer, M., Rafaels, K., Wood, G., Shridharani, J., and Capehart, B. (2012). Brain injuries from blast. Ann. Biomed. Eng. 40, 185-202.

Bass, C. R., Rafaels, K. A., and Salzar, R. S. (2008). Pulmonary injury risk assessment for short-duration blasts. J. Trauma 65, 604.

Bauman, R. A., Ling, G., Tong, L., Januszkiewicz, A., Agoston, D., Delanerolle, N., Kim, Y., Ritzel, D., Bell, R., and Ecklund, J. (2009). An introductory characterization of a combat-casualty-care relevant swine model of closed head injury resulting from exposure to explosive blast. J. Neurotrauma 26, 841-860.

Bowen, I., Fletcher, E., and Richmond, D. (1968). Estimate of Man's Tolerance to the Direct Effects of Air Blast. Technical Progress Report. Washington, DC.

Cernak, I., Merkle, A. C., Koliatsos, V. E., Bilik, J. M., Luong, Q. T., Mahota, T. M., Xu, L., Slack, N., Windle, D., and Ahmed, F. A. (2011). The pathobiology of blast injuries and blastinduced neurotrauma as identified using a new experimental model of injury in mice. Neurobiol. Dis. 41, 538-551.

Cernak, I., Wang, Z., Jiang, J., Bian, X., and Savic, J. (2001). Cognitive deficits following blast injuryinduced neurotrauma: possible involvement of nitric oxide. Brain Inj. 15, 593-612.

Chavko, M., Koller, W. A., Prusaczyk, W. K., and Mccarron, R. M. (2007). Measurement of blast wave by a miniature fiber optic pressure transducer in the rat brain. J. Neurosci. Methods 159, 277-281.

Clemedson, C. J., and Pettersson, H. (1955). Propagation of a high explosive air shock wave through different parts of an animal body. Am. J. Physiol. 184, 119-126.

Cooper, G. (1996). Protection of the lung from blast overpressure by thoracic stress wave decouplers. $J$. Trauma 40, 105S.
Eppinger, R. H., Marcus, J. H., Morgan, R. M., and Engineers, S. O. A. (1984). "Development of dummy and injury index for NHTSA's thoracic side impact protection research program," in Society of Automotive Engineers, Warrendale, PA.

Henderson, L. F., Jia-Huan, M., Akira, S., and Kazuyoshi, T. (1990). Refracinterface. Fluid Dyn. Res. 5, 337-350.

Hooker, D. (1924). Physiological effects of air concussion. Am. J. Physiol. 67, 219.

Hyde, D. (2004). ConWep. Vicksburg, MS: US Army Engineer Research and

Iacobone, E., Bailly-Salin, J., Polito, A., Friedman, D., Stevens, R. D., and Sharshar, T. (2009). Sepsisassociated encephalopathy and its differential diagnosis. Crit. Care Med. 37, S331.

Iremonger, M. (1997). Physics of Detonations and Blast Waves. New York: Butterworth Heinemann.

Kennedy, J. E., Jaffee, M. S., Leskin, G. A., Stokes, J. W., Leal, F. O., and Fitzpatrick, P. J. (2007). Posttraumatic stress disorder and posttraumatic stress disorder-like symptoms and mild traumatic brain injury. $J$. Rehabil. Res. Dev. 44, 895.

Kleinberger, M., Kuppa, S., and Saul, R. (1998). Development of Improved Injury Criteria for the Assessment Systems. Washington, DC: National Highway Traffic Safety Administration.

Leonardi, A. D. C., Bir, C. A., Ritzel, D. V., and Vandevord, P. J. (2011). Intracranial pressure increases during exposure to a shock wave. $J$. Neurotrauma 28, 85-94.

Long, J. B., Bentley, T. L., Wessner, K. A., Cerone, C., Sweeney, S., and Bauman, R. A. (2009). Blast overpressure in rats: recreating a battlefield injury in the laboratory. J. Neurotrauma 26, 827-840.

Loyd, A. M., Nightingale, R. W., Bass, C. R., Mertz, H. J., Frush, D., Daniel, tion of a shock wave at an air - water Development Center. of Advanced Automotive Restraint

\section{ACKNOWLEDGMENTS}

This work was funded in part by the Multidisciplinary Research Initiative (MURI) program (W911MF-10-1-526; University of Pennsylvania as prime institution) through the Army Research Office (ARO). The authors would like to thank Technical Support Working Group (TSWG) and the Massachusetts Institute of Technology, in particular the Institute for Soldier Nanotechnologies, for providing the funding support necessary to perform the experiments.

C., Lee, C., Marcus, J. R., Mukundan, S., and Myers, B. S. (2010). Pediatric head contours and inertial properties for ATD design. Stapp Car Crash J. 54, 167.

Moore, D. F., Jérusalem, A., Nyein, M., Noels, L., Jaffee, M. S., and Radovitzky, R. A. (2009). Computational biology - modeling of primary blast effects on the central nervous system. Neuroimage 47, T10 T20.

Moss, W. C., King, M. J., and Blackman, E. G. (2009). Skull flexure from blast waves: a mechanism for brain injury with implications for helmet design. Phys. Rev. Lett. 103, 108702.

Nyein, M. K., Jason, A. M., Yu, L., Pita, C. M., Joannopoulos, J. D., Moore, D. F., and Radovitzky, R. A. (2010). In silico investigation of intracranial blast mitigation with relevance to military traumatic brain injury. Proc. Natl. Acad. Sci. U.S.A. 107, 20703.

Okie, S. (2005). Traumatic brain injury in the war zone. N. Engl. J. Med. 352, 2043-2047.

Ommaya, A., and Hirsch, A. (1971). Tolerances for cerebral concussion from head impact and whiplash in primates. J. Biomech. 4, 13-21.

Panzer, M. B., Bass, C. R., and Myers, B. S. (2012a). Mesh considerations for finite element blast modeling in biomechanics. Comput. Methods Biomech. Biomed. Engin. doi:10.1080/10255842.10252011.10 629615

Panzer, M. B., Myers, B. S., Capehart, B. P., and Bass, C. R. (2012b). Development of a finite element model for blast brain injury and the effects of CSF cavitation. Ann. Biomed. Eng. doi:10.1007/s10439-10012-1051910432

Panzer, M. B., 'Dale' Bass, C. R., Rafaels, K. A., Shridharani, J., and Capehart, B. P. (2012c). Primary blast survival and injury risk assessment for repeated blast exposures. J. Trauma Acute Care Surg. 72, 454-466.

Prasad, P., and Mertz, H. (1985). "The position of the United States delegation to the ISO working group 6 on the use of HIC in the automotive environment, SAE Paper 851246," in SAE Transactions, Washington.

Pun, P. B. L., Kan, E. M., Salim, A., Li, Z. H., Ng, K. C., Moochhala, S. M., Ling, E.-A., Tan, M. H., and Lu, J. (2011). Low level primary blast injury in rodent brain. Front. Neurol. 2:19. doi:10.3389/fneur.2011.00019

Rafaels, K., "Dale” Bass, C. R., Salzar, R. S., Panzer, M. B., Woods, W., Feldman, S., Cummings, T., and Capehart, B. (2011). Survival risk assessment for primary blast exposures to the head. J. Neurotrauma 18, 2319 2328.

Rafaels, K. A. (2011). Blast Brain Injury Risk. Charlottesville: University of Virginia.

Raum, K., Reißhauer, J., and Brandt, J. (2004). Frequency and resolution dependence of the anisotropic impedance estimation in cortical bone using time resolved scanning acoustic microscopy. J. Biomed. Mater. Res. A 71, 430-438.

Ritenour, A. E., and Baskin, T. W. (2008). Primary blast injury: update on diagnosis and treatment. Crit. Care Med. 36, S311.

Rollins, J. D., Collins, J. S., and Holden, K. R. (2010). United States head circumference growth reference charts: birth to 21 years. J. Pediatr. 156, 907-913; e902.

Ross, A. H., Jantz, R. L., and Mccormick, W. F. (1998). Cranial thickness in American females and males. J. Forensic Sci. 43, 267.

Säljö, A., Arrhén, F., Bolouri, H., Mayorga, M., and Hamberger, A. (2008). Neuropathology and pressure in the pig brain resulting from lowimpulse noise exposure. J. Neurotrauma 25, 1397-1406.

Society of Automotive Engineers. (1995). J211-1 instrumentation for impact testing - part 1 - electronic instrumentation. Available at: http://standards.sae.org/j211/1_ 200707/ 
Suneson, A., Axelsson, H., Hjelmqvist, H., Medin, A., and Persson, J. (2000). Physiological changes in pigs exposed to a blast wave from a detonating high-explosive charge. Mil. Med. 165, 119-126.

United States Department of Transportation. (2006). Laboratory Test Procedure for Motorcycle Helmets. FMVSS No. 218. TP218-06. Washington, DC: National Highway Traffic Safety Administration, Office of Vehicle Safety Compliance.

Versace, J. (1971). "A review of the severity index," in Society of
Automotive Engineers, Warrendale, PA.

doi:10.1136/injuryprev-2011040277

Warden, D., Ryan, L., and Helmick, K. (2005). War Neurotrauma: The Defense and Veterans Brain Injury Center (DVBIC) Experience at Walter Reed Army Medical Center (WRAMC). Washington, DC: Defense and Veterans Brain Injury Center, Walter Reed Army Medical Center.

Wood, G., Panzer, M., Shridharani, J., Matthews, K., Capehart, B., Myers, B., and Bass, C. (2012). Attenuation of blast pressure behind ballistic protective vests. Inj. Prev.
Conflict of Interest Statement: The authors declare that the research was conducted in the absence of any commercial or financial relationships that could be construed as a potential conflict of interest.

Received: 30 November 2011; accepted: 11 April 2012; published online: 08 May 2012.

Citation: Shridharani JK, Wood GW, Panzer MB, Capehart BP, Nyein MK, Radovitzky RA and Bass
CR' (2012) Porcine head response to blast. Front. Neur. 3:70. doi: 10.3389/fneur.2012.00070

This article was submitted to Frontiers in Neurotrauma, a specialty of Frontiers in Neurology.

Copyright (C) 2012 Shridharani, Wood, Panzer, Capehart, Nyein, Radovitzky and Bass. This is an open-access article distributed under the terms of the Creative Commons Attribution Non Commercial License, which permits non-commercial use, distribution, and reproduction in other forums, provided the original authors and source are credited. 